\title{
Introducing a nationwide registry: the Swiss study on aneurysmal subarachnoid haemorrhage (Swiss SOS)
}

\author{
Bawarjan Schatlo • Christian Fung • Ali-Reza Fathi • \\ Martin Sailer • Kerstin Winkler • Roy Thomas Daniel • \\ Philippe Bijlenga • Peter Ahlborn • Martin Seule • \\ Daniel Zumofen • Michael Reinert • Christoph Woernle • \\ Martin Stienen - Marc Levivier • Gerhard Hildebrandt • \\ Luigi Mariani • René Bernays • Javier Fandino • \\ Andreas Raabe • Emanuela Keller • Karl Schaller
}

Received: 18 May 2012 / Accepted: 13 September 2012 /Published online: 6 October 2012

(C) Springer-Verlag Wien 2012

\begin{abstract}
Background Aneurysmal subarachnoid haemorrhage (aSAH) is a haemorrhagic form of stroke and occurs in a younger population compared with ischaemic stroke or intracerebral haemorrhage. It accounts for a large proportion of productive life-years lost to stroke. Its surgical and medical treatment represents a multidisciplinary effort. Due to the complexity of the disease, the management remains difficult to standardise and quality of care is accordingly difficult to assess.

Objective To create a registry to assess management parameters of patients treated for aSAH in Switzerland.

Methods A cohort study was initiated with the aim to record characteristics of patients admitted with aSAH, starting
\end{abstract}

B. Schatlo $\cdot$ P. Bijlenga $\cdot$ K. Schaller

Department of Neurosurgery, Geneva University Hospital,

Geneva, Switzerland

C. Fung $\cdot$ M. Reinert $\cdot$ A. Raabe

Department of Neurosurgery (2a) Department of Intensive Care

Medicine, Inselspital,

Bern, Switzerland

A.-R. Fathi $\cdot$ J. Fandino

Department of Neurosurgery, Kantonsspital Aarau,

Aarau, Switzerland

M. Sailer $\cdot$ D. Zumofen $\cdot$ L. Mariani

Department of Neurosurgery, Basel University Hospital,

Basel, Switzerland

K. Winkler $\cdot$ C. Woernle $\cdot$ R. Bernays $\cdot$ E. Keller

Department of Neurosurgery/Neurointensive Care Unit, University

Hospital of Zürich,

Zürich, Switzerland
January 1st 2009. Ethical committee approval was obtained or is pending from the institutional review boards of all centres. In the study period, seven Swiss hospitals (five university [U], two non-university medical centres) harbouring a neurosurgery department, an intensive care unit and an interventional neuroradiology team so far agreed to participate in the registry (Aarau, Basel [U], Bern [U], Geneva [U], Lausanne [U], St. Gallen, Zürich [U]). Demographic and clinical parameters are entered into a common database. Discussion This database will soon provide (1) a nationwide assessment of the current standard of care and (2) the outcomes for patients suffering from aSAH in Switzerland. Based on data from this registry, we can conduct cohort

\section{R. T. Daniel $\cdot$ M. Levivier}

Department of Neurosurgery, Lausanne University Hospital,

Lausanne, Switzerland

P. Ahlborn • M. Seule • M. Stienen • G. Hildebrandt Department of Neurosurgery, Kantonsspital St. Gallen, St. Gallen, Switzerland

K. Schaller $(\bowtie)$

Department of Neurosurgery, Hôpitaux Universitaires de Genève, Faculty of Medicine, University of Geneva,

Rue Gabrielle Perret-Gentil 4,

1211 Geneva 14, Switzerland

e-mail: karl.schaller@hcuge.ch 
comparisons or design diagnostic or therapeutic studies on a national level. Moreover, a standardised registration system will allow healthcare providers to assess the quality of care.

Keywords Subarachnoid haemorrhage · Intracranial aneurysm $\cdot$ Cerebral aneurysm

\section{Introduction}

Overview and socioeconomic impact

SAH is a type of haemorrhagic stroke, which occurs due to rupture of an intracranial aneurysm in $85 \%$ of cases. The incidence of aSAH between regions of the world is highly variable (from 3 in parts of South America to over 20 per 100,000 person-years in Japan) [3]. aSAH represents $5 \%$ of all cerebrovascular accidents. In contrast to the more prevalent ischaemic stroke and intracerebral haemorrhage which affect older age-groups, half of the patients suffering from aSAH are younger than 55 years. aSAH thus accounts for a quarter of all productive life years lost to stroke [11]. Patients admitted and diagnosed with aSAH have long hospital stays (average in patients over 65 years: 22 days [18]) and most are at least temporarily monitored in a neurointensive care unit. The cost of hospitalisation of a "low severity" case of aSAH was estimated to be $35,000 \$$ in the US [14]. An estimated 437 million EUR are spent per year on the treatment of aSAH in Germany alone [4]. In addition to the socioeconomic impact, the disease affects the quality of life of more than nine out of ten patients even 1 year after discharge [15].

\section{Necessity of a nationwide registry}

The management of aSAH in Switzerland has not been assessed on a national level to date. We united large neurovascular centres in Switzerland to create a registry for aSAH. This registry helps collect clinical and management data from different centres and pools it in one common database. It may provide referring caregivers and healthcare providers with a critical tool to assess the quality of care in a disease which has a high socio-economic burden. Moreover, it may serve as a tool to foster scientific collaboration and address a number of remaining questions about the management of aSAH in the future.

Regarding SAH, data from the federal statistics bureau of Switzerland are based strictly on ICD-10 codes provided by hospitals and show an estimate of 13 per 100,000 in a population of roughly 8 million (http://bfs.admin.ch). These numbers, however, are not referring to aneurismal SAH exclusively and thus exceed the numbers which we expect to obtain. In the first years of the registry we cannot claim complete recruitment of SAH patients throughout Switzerland, and the goal is therefore that assessment of incidence will be performed later on.

Dilemmas in the management of aSAH

Aneurysmal SAH has a poor prognosis, with a mortality of about $40 \%$ and morbidity including neurological deficits affecting about one-third of patients. Prognosis is not only limited by the bleed itself with the associated early brain injury but also by conditions such as hydrocephalus, delayed ischaemic neurological deficits and extracranial disease [13]. The following points briefly illustrate exemplary domains where further large-scale studies are necessary to answer imminent questions on the optimal management of aSAH. These and other points have been included in the current registry.

\section{Aneurysm treatment}

Rebleeding is the most dangerous complication of aSAH and occurs mostly within hours or days of the initial bleed. Therefore, it is mandatory to perform aneurysm treatment early to prevent re-rupture. The main options for aneurysm occlusion are surgical clipping and endovascular therapy. The treatment decision is commonly taken after interdisciplinary discussion based on aneurysm size, location and the patient's constitution. Surgical as well as interventional techniques have undergone significant development in recent years, prompting a continuous critical assessment of safety, efficacy and longterm outcome. Stents as endovascular flow diverters have recently expanded our treatment options in selected cases of aneurysms. Comparison between these rapidly evolving techniques has become increasingly difficult.

\section{Management of hydrocephalus}

About $15 \%$ of patients develop acute hydrocephalus after aSAH [8]. The standard treatment for acute hydrocephalus is cerebrospinal fluid drainage by an external ventricular drain. However, recent studies have re-assessed the possibility of lumbar drainage. The optimal management of subacute or late hydrocephalus still remains a matter of debate. Uncertainty also remains about the best timing to perform surgery for a ventriculo-peritoneal shunt versus trying repeated lumbar punctures.

\section{Detection of delayed ischaemic neurological deficit}

Delayed ischaemic neurological deficits occur in a significant proportion of patients after aSAH and CT-proven infarcts occur in $40 \%$ [16]. It is suspected that the number of patients suffering cerebral ischaemia after aSAH has been 
underestimated. Both the prevention, detection and the treatment of delayed ischaemia remain unsolved problems. A number of diagnostic bedside methods for continuous monitoring of cerebral blood flow, oxygenation and metabolism are available, but their respective limitations have hitherto prevented universal acceptance [10, 19]. Potential drawbacks include a small sample volume and the inability to monitor cerebral blood flow directly. Measurements are often limited to a small sample volume with the potential risk of missing cerebral ischaemia in other vascular territories. Moreover, recent insights into alterations of cerebral blood flow in response to waves of cortical depolarisation as precursors of ischaemia may improve the early detection of delayed ischaemic events. However, the development of practicable and widely available monitoring equipment is still in the experimental stages [6]. Future approaches using advanced bioinformatics may be required for applying multi-parameter monitoring to clinical care [9].

\section{Prevention of delayed ischaemic neurological deficits}

The fact that delayed ischaemia after aSAH occurs several days after the bleed in patients who are already in the hospital makes this complication potentially preventable. Most of the early efforts in preventing these deficits were aimed at the treatment of angiographic cerebral vasospasm which occurs between days 4 and 14 of SAH. Interestingly, the reduction of angiographic vasospasm has so far not translated to an improvement in patient outcome [12]. The calcium-channel blocker nimodipine has a modest impact on delayed cerebral ischaemia and is the only pharmaceutical treatment approved for the treatment of delayed cerebral ischaemia and vasospasm [5]. However, its side effects, particularly systemic hypotension, significantly limit its use in this patient population where therapeutic hypertension is mandatory. Local delivery of vasodilators such as nicardipine pellets was found to be of benefit in patients undergoing surgery for aSAH [2]. While interventional balloon dilation or injection of vasodilatory substances for symptomatic vasospasm are established procedures, their timing and risks are debatable. Prophylactic angioplasty has not improved outcome [21].

\section{Outcome measures}

Aneurysmal SAH for the larger part affects people in their working age. Therefore, even slight neurological disturbances can have a major impact on their ability to return to their previous occupation. Some authors argued that the presumed lack of efficacy for drugs reversing delayed cerebral vasospasm may be due to the absence of adequate outcome measures. Such outcome measures include a thorough neurological test battery as well as quality of life parameters. A registry on a national level could have a sufficient caseload to help develop and validate testing batteries including quality of life questionnaires such as the modified Rankin Scale or the Glasgow Outcome Scale Extended [20]. Our hope is also that by standardising outcome measures at a later point in this study, follow-up will ultimately improve.

\section{Materials and methods}

Neurovascular teams at seven Swiss hospitals (five university [U], two non-university medical centres) which treat patients with aSAH held two initiation meetings in 2009 and 2010 (Aarau, Basel [U], Bern [U], Geneva [U], Lausanne [U], St. Gallen, Zürich [U]). Participating centres have a neurosurgery department, an intensive care unit and an endovascular team and are tertiary referral centres within Switzerland. The Swiss SOS registry is designed as a multicentre database with the same parameters (an overview is provided in Table 1) which each participating centre manages independently. Due to missing values in this preliminary sample from the feasibility period, not all patients had complete data sets, resulting in an occasionally lower number of totals. Anonymous demographic and clinical data are recorded for all patients with aSAH for a permanent data collection. Where necessary, this is done retrospectively for cases admitted since 01.01.2009. Ethical committee approval was obtained or is pending from the institutional review boards of all centres.

\section{Patient recruitment/inclusion and exclusion criteria}

Inclusion criteria: All patients admitted with a diagnosis of aSAH at one of the participating centres are entered into the local database. Residents from outside Switzerland can therefore be accepted for treatment in Switzerland and vice-versa. This fluctuation was not quantified as the goal of the database was to unify assessment of SAH management in Switzerland, regardless of the patients' origin.

Patient data are anonymous. The local databases can be fused into a common centralised file.

Exclusion criteria: Patients in whom the source of haemorrhage could not be identified (angiogram-negative SAH) or SAH with other causes than cerebral aneurysms.

The clinical data of the main hospitalisation (time-point of SAH) represents the central part of the database. Some preliminary data from the feasibility assessment period in 2009 is presented in Table 2 to provide an overview on the demographic and clinical status of patients admitted with SAH in Switzerland. Data on clinical status at follow-up can be entered for up to year 5 post SAH. Individual length of follow-up for patients with aSAH remains at the discretion of each centre. 
Table 1 Simplified overview of basic parameters

\begin{tabular}{|c|c|c|}
\hline Demographics & $\begin{array}{l}\text { Unique ID .......... } \\
\text { Sex: female ... male ... }\end{array}$ & $\begin{array}{l}\text { Age at ictus .......... } \\
\text { Tobacco use ... }\end{array}$ \\
\hline Date and time of... & $\begin{array}{l}\text { Ictus } \ldots \ldots \ldots \ldots \ldots \ldots \\
\text { ICU days } \ldots \ldots \ldots \ldots \ldots \ldots\end{array}$ & $\begin{array}{l}\text { Admission } . . . \ldots \ldots \ldots \ldots \\
\text { Discharge home } \ldots \ldots \ldots \ldots \ldots \ldots\end{array}$ \\
\hline Admission status & $\begin{array}{l}\text { Glasgow Coma Scale ....... } \\
\text { Neurological deficit ... }\end{array}$ & $\begin{array}{l}\text { Intubated/sedated ....... } \\
\text { Pupil status ...... }\end{array}$ \\
\hline Imaging & $\begin{array}{l}\text { SAH blood distribution } \\
\text { Aneurysm localisation }+ \text { type } \\
\text { Largest diameter }(\mathrm{mm}) \ldots \ldots \\
\text { Other aneurysms }\end{array}$ & $\begin{array}{l}\text { Fisher grade } \ldots \ldots \ldots \ldots \\
\ldots \ldots \ldots \ldots \ldots \ldots \ldots \ldots \ldots \\
\text { Aneurysm side } \ldots \ldots \ldots \ldots \\
\ldots \ldots \ldots \ldots \ldots \ldots \ldots \ldots \ldots\end{array}$ \\
\hline Treatment & $\begin{array}{l}\text { Aneurysm: } \\
\text { Hydrocephalus: }\end{array}$ & $\begin{array}{l}\text { Coil ..... Clip ...... Stent ...... } \\
\text { Ventriculostomy ...... } \\
\text { Lumbar drain ...... } \\
\text { Ventriculoperitoneal shunt ...... } \\
\text { Craniectomy ...... } \\
\text { Haematoma removal ...... }\end{array}$ \\
\hline Vasospasm & Delayed neurol. deficit ...... & Balloon dilation ...... \\
\hline Outcome & At discharge, 1 year, 5 years & $\begin{array}{l}\text { Neurological deficit ...... } \\
\text { Modified Rankin ...... } \\
\text { Glasgow Outcome Scale ...... }\end{array}$ \\
\hline
\end{tabular}

Statistical analysis

Statistical analysis and data quality evaluation will be performed by a dedicated statistician.

Table 2 Overview on preliminary pilot data from 2009

\begin{tabular}{|c|c|c|c|}
\hline & & $n$ & $\%$ \\
\hline Age (years; median, range) & $55(17-87)$ & & \\
\hline \multirow[t]{2}{*}{ Sex } & Female & 187 & $67.3 \%$ \\
\hline & Male & 91 & $33.7 \%$ \\
\hline \multirow{4}{*}{$\begin{array}{l}\text { Clinical status at admission } \\
\text { (Glasgow Coma Scale) }\end{array}$} & GCS 15 & 111 & $40.5 \%$ \\
\hline & GCS 13-14 & 68 & $24.8 \%$ \\
\hline & GCS $7-12$ & 30 & $11.0 \%$ \\
\hline & GCS 3-7 & 65 & $23.7 \%$ \\
\hline \multirow[t]{6}{*}{ Aneurysm treatment } & Clip & 115 & $42.9 \%$ \\
\hline & Coil & 105 & $39.2 \%$ \\
\hline & Clip + coil & 12 & $4.5 \%$ \\
\hline & Coil + stent & 6 & $2.2 \%$ \\
\hline & Stent & 4 & $1.5 \%$ \\
\hline & None & 26 & $9.7 \%$ \\
\hline \multirow{7}{*}{$\begin{array}{l}\text { Outcome at discharge } \\
\text { (modified Rankin scale) }\end{array}$} & 0: No symptoms & 32 & $13.3 \%$ \\
\hline & 1: No disability (dis.) & 70 & $29.2 \%$ \\
\hline & 2: Slight dis. & 45 & $18.8 \%$ \\
\hline & 3: Moderate dis. & 31 & $12.9 \%$ \\
\hline & 4: Moderately severe dis. & 30 & $12.5 \%$ \\
\hline & 5: Severe dis. & 24 & $10.0 \%$ \\
\hline & 6: Dead & 40 & $16.7 \%$ \\
\hline
\end{tabular}

\section{Discussion}

Our aim is to create an observational database on clinical management aspects of aSAH. The severity of the disease and its many complications make aSAH a challenging disease to treat from the first day to the day where the patient can leave the hospital, often weeks later. aSAH patients can be categorised by clinical status at admission (World Federation of Neurological Surgeons Scale [17]), severity of haemorrhage (Fisher scale [7]), aneurysm localisation, presence of hydrocephalus, epilepsy or even extracranial disease (e.g. cardiac arrhythmia, pulmonary oedema). While all participating Swiss centres have a "high volume" [1] with more than 20 patients per year, each patient requires individualised decision-making based on a multitude of parameters. Moreover, the patient is treated by a team including among others neurosurgeons, neuro-interventionalists, neurointensivists and anaesthesiologists. The evident lack of consensus on optimal management prompts a large-scale effort which cannot be mustered by one centre alone. For a population of about 8 million, Switzerland has several neurovascular centres with a high standard, and a common Swiss registry can serve multiple purposes:

Assessment of the status quo

The management of patients with aSAH in Switzerland has not yet been explored on a national level. A common database will help provide such an assessment. 
Simplicity and standardisation

Our aim is to provide a database on aSAH which has a limited number of parameters and remains simple in its use. The parameters should be applicable in a similar manner by investigators from all centres and are therefore standardised.

\section{Socioeconomic parameters and patient outcome}

Age, duration of hospitalisation (total duration and intensive care unit) and modified Rankin Scale at discharge as well as at follow-up are recorded in the database and give an estimate of the immediate socioeconomic burden of aSAH. Moreover, the database can be extended using quality of life measures.

Clinical status and management

Basic information on clinical status at admission, treatment modalities as well as delayed complications are recorded. The presence of multiple aneurysms and their impact on management can be derived from the datasets.

\section{Quality of care}

In response to increasing medical knowledge, medical disciplines are increasingly evolving towards areas of subspecialty. This tendency is also tangible in Switzerland where federal efforts are focused towards developing reference centres which are staffed and equipped appropriately and which will receive patients with a specific pathology from beyond their traditional recruitment area.

Healthcare providers are also asked to justify expenses by documenting the quality of care. The ability to provide outcomes in a standardised manner will enable clinicians to anticipate requests of insurers and public institutions. This is particularly important since the costs of neurointensive care management are high and medical evidence is often lacking to support our individual-based treatment decisions.

Critical mass for research and further studies

Swiss neurovascular centres traditionally have shown a strong interest in the improvement of patient care through scientific research. To unite several high-level neurovascular centres may improve the visibility of a geographically limited community with similar research interests. The coordination for larger-scale studies or translational research efforts could be facilitated.

\section{Funding}

Currently, the Swiss SOS is a loose framework of a "neurovascular interest group". At present, no funding was applied for. As the first results of the collaboration will surface, hypotheses for potential scientific applications will be discussed and funding will be applied for to answer specific questions or conduct a project of common interest.

\section{Limitations}

At the beginning, our database will be retrospective and observational. The assessed parameters (provided in Table 1) are of relative simplicity in order to limit time and expenses for the investigators. In the first phase of the project, there will be no study nurse in the majority of centres due to the lack of starting funds as described above. Each centre has assigned a physician who is responsible for quality clearance before data submission to the registry.

\section{Conclusion}

The creation of a national network for aSAH is a logical step forward in documenting treatment and outcome for a complex disease. The first goal is the improvement of patient management by standardisation and comparability. Furthermore, the registry may serve as an initiator for studies with scientific hypotheses regarding diagnosis and treatment of aSAH.

Acknowledgements Collaborators: Stephan Jakob (Bern, Switzerland), Jürgen Beck (Bern, Switzerland), Yvan Gasche (Geneva, Switzerland), Vitor Mendes-Pereira (Geneva, Switzerland), Sofia Nistor (Lausanne, Switzerland), Niklaus Krayenbühl (Zurich, Switzerland), Hiroki Danura (Aarau, Switzerland).

Conflicts of interest None.

\section{References}

1. Barker FG 2nd, Amin-Hanjani S, Butler WE, Ogilvy CS, Carter BS (2003) In-hospital mortality and morbidity after surgical treatment of unruptured intracranial aneurysms in the United States, 1996-2000: the effect of hospital and surgeon volume. Neurosurgery 52:995-1007, discussion 1007-1009

2. Barth M, Capelle HH, Weidauer S, Weiss C, Munch E, Thome C, Luecke T, Schmiedek P, Kasuya H, Vajkoczy P (2007) Effect of nicardipine prolonged-release implants on cerebral vasospasm and clinical outcome after severe aneurysmal subarachnoid hemorrhage: a prospective, randomized, double-blind phase IIa study. Stroke 38:330-336

3. de Rooij NK, Linn FH, van der Plas JA, Algra A, Rinkel GJ (2007) Incidence of subarachnoid haemorrhage: a systematic review with emphasis on region, age, gender and time trends. J Neurol Neurosurg Psychiatry 78:1365-1372

4. Dodel R, Winter Y, Ringel F, Spottke A, Gharevi N, Muller I, Klockgether T, Schramm J, Urbach H, Meyer B (2010) Cost of illness in subarachnoid hemorrhage: a German longitudinal study. Stroke41:2918-2923 
5. Dorhout Mees SM, Rinkel GJ, Feigin VL, Algra A, van den Bergh WM, Vermeulen M, van Gijn J (2007) Calcium antagonists for aneurysmal subarachnoid haemorrhage. Cochrane Database Syst Rev (3):CD000277

6. Dreier JP (2011) The role of spreading depression, spreading depolarization and spreading ischemia in neurological disease. Nat Med 17:439-447

7. Fisher CM, Kistler JP, Davis JM (1980) Relation of cerebral vasospasm to subarachnoid hemorrhage visualized by computerized tomographic scanning. Neurosurgery 6:1-9

8. Graff-Radford NR, Torner J, Adams HP Jr, Kassell NF (1989) Factors associated with hydrocephalus after subarachnoid hemorrhage. A report of the Cooperative Aneurysm Study. Arch Neurol 46:744-752

9. Hemphill JC, Andrews P, De Georgia M (2011) Multimodal monitoring and neurocritical care bioinformatics. Nat Rev Neurol 7:451-460

10. Jaeger M, Soehle M, Schuhmann MU, Winkler D, Meixensberger J (2005) Correlation of continuously monitored regional cerebral blood flow and brain tissue oxygen. Acta Neurochir (Wien) 147:51-56, discussion 56

11. Johnston SC, Selvin S, Gress DR (1998) The burden, trends, and demographics of mortality from subarachnoid hemorrhage. Neurology 50:1413-1418

12. Macdonald RL, Higashida RT, Keller E, Mayer SA, Molyneux A, Raabe A, Vajkoczy P, Wanke I, Bach D, Frey A, Marr A, Roux S, Kassell N (2011) Clazosentan, an endothelin receptor antagonist, in patients with aneurysmal subarachnoid haemorrhage undergoing surgical clipping: a randomised, double-blind, placebo-controlled phase 3 trial (CONSCIOUS-2). Lancet Neurol 10:618-625

13. Macdonald RL, Pluta RM, Zhang JH (2007) Cerebral vasospasm after subarachnoid hemorrhage: the emerging revolution. Nat Clin Pract Neurol 3:256-263

14. Maud A, Lakshminarayan K, Suri MF, Vazquez G, Lanzino G, Qureshi AI (2009) Cost-effectiveness analysis of endovascular versus neurosurgical treatment for ruptured intracranial aneurysms in the United States. J Neurosurg 110:880-886

15. Meyer B, Ringel F, Winter Y, Spottke A, Gharevi N, Dams J, Balzer-Geldsetzer M, Mueller IK, Klockgether T, Schramm J, Urbach H, Dodel R (2010) Health-related quality of life in patients with subarachnoid haemorrhage. Cerebrovasc Dis 30:423-431

16. Rabinstein AA, Weigand S, Atkinson JL, Wijdicks EF (2005) Patterns of cerebral infarction in aneurysmal subarachnoid hemorrhage. Stroke 36:992-997

17. Rosen DS, Macdonald RL (2005) Subarachnoid hemorrhage grading scales: a systematic review. Neurocrit Care 2:110-118

18. Taylor CL, Yuan Z, Selman WR, Ratcheson RA, Rimm AA (1997) Mortality rates, hospital length of stay, and the cost of treating subarachnoid hemorrhage in older patients: institutional and geographical differences. J Neurosurg 86:583-588

19. Vajkoczy P, Horn P, Thome C, Munch E, Schmiedek P (2003) Regional cerebral blood flow monitoring in the diagnosis of delayed ischemia following aneurysmal subarachnoid hemorrhage. J Neurosurg 98:1227-1234

20. Wilson JT, Pettigrew LE, Teasdale GM (1998) Structured interviews for the Glasgow Outcome Scale and the extended Glasgow Outcome Scale: guidelines for their use. J Neurotrauma 15:573-585

21. Zwienenberg-Lee M, Hartman J, Rudisill N, Madden LK, Smith K, Eskridge J, Newell D, Verweij B, Bullock MR, Baker A, Coplin W, Mericle R, Dai J, Rocke D, Muizelaar JP (2008) Effect of prophylactic transluminal balloon angioplasty on cerebral vasospasm and outcome in patients with Fisher grade III subarachnoid hemorrhage: results of a phase II multicenter, randomized, clinical trial. Stroke; J Cereb Circ 39:1759-1765

\section{Comment}

Here we have a useful and erudite discussion of the natural history and management issues in aSAH patients, framed in a prospective registry that the authors have developed for major Swiss neurosurgical units. The discussion of the registry is of course theoretical at present as there are no data yet. The potential value of the information is great, and the feasibility of acquiring useful data is high since the country is a small one and all of the major units have been recruited to collaborate. Certainly we would have more difficulty with such a project in the USA, where aSAH care is delivered in many ways in many centres with great variance in management styles.

We look forward with anticipation to a broad comprehensive sample and the acquisition of quality information regarding the clinical issues that challenge us all, including best primary treatment option for optimised outcomes, prevalence of hydrocephalus, best management strategies for DIND, and the like. If the dataset is comprehensive, as we hope it will be, even questions that are not currently framed can be addressed in later years by accessing the sample. As the authors have pointed out, the registry also lends itself well to assessment and documentation of quality, and if properly managed, will be a good tool for prominent neurosurgeons (the investigators) to influence and shape payer and government policies regarding the management of these resource intense high-consumption patients.

Christopher Miranda Loftus

Philadelphia, USA 